\title{
THE INFLUENCE OF SOLVENTS ON THE DRYING OF LINSEED OIL.
}

\author{
Br W. E. F. POWNEY. \\ (Read at the Mecting, April 6, 1910.)
}

THe frequent and increasing employment of substitutes for oil of turpentine in the paint and varnish industries has made some practical comparison of these solvents desirable, and the present investigation was undertaken with a view to ascertaining the relative merits of the solvents generally used in this connection.

The composition of commercial turpentine substitutes has already been dealt with by J. H. Coste (Avalyst, 1910, 112-117), and it will be seen by reference to the paper in question that, generally speaking, they consist of petroleum hydrocarbons (both aliphatic and cyclic), either alone or in admixture with comparatively small quantities of turpentine. Further, it has been shown by the same author that, by Armstrong's method of polymerisation, the turpentine can be removed from these mixtures without appreciably affecting the composition of the petroleum hydrocarbons--a point of some importance.

With regard to the practical utility of the solvents, turpentine is generally accepted as the most suitable for use with linseed oil, its function being regarded as that of an oxygen (or ozone) carrier which assists in the drying of the oil. In addition, the resinification of part of the turpentine during its evaporation is supposed to produce a more elastic coat than would otherwise be obtained. The petroleum hydrocarbons, on the other hand, are stated merely to evaporate without imparting any drying properties; but it would at least seem probable that the addition of any solvent of suitable volatility might assist the drying in some degree, owing to the continuous exposure of new particles of the oil to the atmosphere by the evaporation of the solvent. 
The drying experiments of the present investigation and the volatility tests on the solvents were made in circular, flat-bottomed metal dishes $\frac{1}{2}$ inch deep and $2 \frac{1}{2}$ inches in diameter. Equal volumes (known weights) of the oil and solvent were mixed in these dishes, and weighed at intervals during their exposure to the atmosphere. The experiments were conducted in sets, and, the conditions for all the solvents of any one set being identical, the individual results of that set are strictly comparable among themselves; but, of course, not with those of another. It will be evident that, other things being equal, the greatest increase in weight of the oil during a given time would correspond with the greatest amount of oxidation, and thus indicate the most efficient solvent.

The oils employed in the tests were raw and boiled linseed oil ; they were used singly and together. Physical and chemical examination indicated that both samples were of good quality, the boiled oil containing manganese compounds $=0.11$ per cent. Mn added as a drier in the process of manufacture. The turpentine used was freshly distilled from the genuine American product, the fraction passing over between $160^{\circ}$ and $170^{\circ} \mathrm{C}$. being kept for the tests.

In the selection of turpentine substitutes it was considered highly desirable that, for purposes of comparison, they should be definitely related. Accordingly, a substitute consisting only of petroleum hydrocarbons was prepared by submitting a commercial sample to the polymerisation process already referred to; while another was made up by mixing a portion of this petroleum with one-fifth of its volume of the above turpentine distillate. For our present convenience the term "substitute" will be applied to the mixture of petroleum and turpentine, the petroleum solvent being simply designated "petroleum."

The three solvents were stored in stoppered bottles, and volatility tests were made upon them (simultaneously with each set of drying experiments) by exposing equal volumes - weighed quantities - of each in the metal dishes as already described. Two days after their preparation both the substitute and the petroleum were completely volatile in less than twenty-four hours, but the turpentine gave 0.2 per cent. of non-volatile residue, evidently due to resinification. In making a comparison of the solvents it therefore became necessary to make allowance for this fixed residue, in order that the increase in weight of the oil might be fairly ascribed to oxidation. But, since the amount of residue left by the turpentine depends upon the rate of volatilisation, and as the volatilisation of any solvent mixed with oil must necessarily proceed more slowly than when alone, it is evident that the exact determination of, or the close approximation to, the amount of solvent or solvent-product retained by the oil at any given time becomes a very important matter when the utility of the solvent is to be measured by the increase in weight of the oil with which it is mixed. This difficulty was overcome by making blank experiments with each set, using similar quantities of the solvents mixed with nondrying oil of about the same specific gravity as the linseed oil, a mixture of pure olive and castor oils being used for this purpose.

Four sets of experiments were conducted, the first being on raw linseed oil, the second on a mixture of equal volumes of raw and boiled oils, and the third and fourth on boiled oil. Each set comprised twelve dishes: two each of linseed oil 
alone, and with turpentine, "substitute," and "petroleum "respectively; two of non-drying oil with turpentine; and one each of non-drying oil with "substitute" and "petroleum" respectively. Volatility tests of the three solvents were made simultaneously.

In working out the results for any given time, the increase in weight of the non-drying oil was calculated as a percentage of solvent originally present. The amount of solvent so retained was then calculated for each quantity of linseed oil present, and deducted from the gross increase of the latter in each case. The net values so obtained were finally calculated to percentages on the weights of linseed oil taken. The following tables show the results obtained, and also indicate the volatility of each solvent-alone and with non-drying oil-for each set of experiments :

I. Raw Oil Experiments.

(c) Volatility of Solvents.

(Percentage by weight.)

\begin{tabular}{|c|c|c|c|c|c|c|}
\hline \multirow{2}{*}{ Time. } & \multicolumn{3}{|c|}{ Alone. } & \multicolumn{3}{|c|}{ With Non-drying Oil. } \\
\hline & Turpentine & Substitute. & Petroleum. & Turpentine. & Sulstitute. & Petroleum. \\
\hline $\begin{array}{ll}3 \text { hours } & \ldots \\
5 \quad, & \cdots \\
24, & \ldots\end{array}$ & $\begin{array}{l}93 \cdot 2 \\
99 \cdot 3 \\
99 \cdot 8\end{array}$ & $\begin{array}{r}99 \cdot 3 \\
99 \cdot 6 \\
100 \cdot 0\end{array}$ & $\begin{array}{r}99 \cdot 5 \\
99 \cdot 7 \\
100 \cdot 0\end{array}$ & $\begin{array}{l}90 \cdot 9 \\
96 \cdot 9 \\
99 \cdot 2\end{array}$ & $\begin{array}{l}85 \cdot 1 \\
93 \cdot 3 \\
98 \cdot 2\end{array}$ & $\begin{array}{l}83 \cdot 4 \\
91 \cdot 5 \\
97 \cdot 9\end{array}$ \\
\hline $\begin{array}{cc}\text { Maximum } & \text { vola- } \\
\text { tility } & \ldots\end{array}$ & $99 \cdot 8$ & $100 \cdot 0$ & $100 \cdot 0$ & $99 \cdot 4$ & $99 \cdot 3$ & $99 \cdot 4$ \\
\hline
\end{tabular}

(b) Net Increase in Weight of the Linseed Oil.

\begin{tabular}{|c|c|c|c|c|c|}
\hline & & \multicolumn{4}{|c|}{ Percentage Net Increase in- } \\
\hline & & ;) Days. & 5 Days. & $i$ Hays. & 10 Inays. \\
\hline \multirow{2}{*}{\multicolumn{2}{|c|}{$\begin{array}{rll}\text { Raw oil alone ... } & . . \\
, & \text { with turpentine } & . . \\
" & \text { with "substitute " } & . . \\
, & \text { with "petroleum " }\end{array}$}} & $\begin{array}{l}0 \cdot 08 \\
0 \cdot 36 \\
0 \cdot 42 \\
0 \cdot 3 \tilde{\jmath}\end{array}$ & $\begin{array}{l}0 \cdot 25 \\
0 \cdot 77 \\
0 \cdot 48 \\
0 \cdot 39\end{array}$ & $\begin{array}{l}0 \cdot 79 \\
1 \cdot 05 \\
0 \cdot 73 \\
0 \cdot 62\end{array}$ & $\begin{array}{l}1 \cdot 78 \\
1.85 \\
1.50 \\
1.39\end{array}$ \\
\hline & & \multicolumn{4}{|c|}{ Relatise Values of Solvents (Turpentine $=100$ ). } \\
\hline $\begin{array}{c}\text { Raw oil alone ... } \\
\quad, \quad \text { with turpentine } \\
\text { ", with "substitute" } \\
\text { ", with "petroleum" }\end{array}$ & \begin{tabular}{l|}
$\cdots$ \\
$\cdots$ \\
$\cdots$ \\
$\cdots$
\end{tabular} & $\begin{array}{r}22 \\
100 \\
117 \\
97\end{array}$ & $\begin{array}{r}32 \\
100 \\
62 \\
50\end{array}$ & $\begin{array}{r}75 \\
100 \\
69 \\
59\end{array}$ & $\begin{array}{r}96 \\
100 \\
80 \\
75\end{array}$ \\
\hline
\end{tabular}


II. Raw and Bolled Oils (Equal Volumes).

(a) Volatility of Solvonts.

(Percentage by weight.)

\begin{tabular}{|c|c|c|c|c|c|c|}
\hline \multirow{2}{*}{ Time. } & \multicolumn{3}{|c|}{ Alone. } & \multicolumn{3}{|c|}{ With Non-drying Oil. } \\
\hline & Turpentine. & Substitute. & l'etroleum. & Turpentine. & Substitute. & Petroleum. \\
\hline 3 hours & $91 \cdot 8$ & $96 \cdot 9$ & $98 \cdot 5$ & $87 \cdot 1$ & $84 \cdot 1$ & $83 \cdot 9$ \\
\hline $5 \quad$, & $99 \cdot 1$ & 999 & $100 \cdot 0$ & $95 \cdot \overline{8}$ & $92 \cdot 8$ & 92.5 \\
\hline 24 & $99 \cdot 2$ & $99 \cdot 9$ & $100 \cdot 0$ & $98 \cdot 0$ & $97 \cdot 0$ & $96 \cdot 9$ \\
\hline $\begin{array}{cc}\text { Maximum } & \text { vola- } \\
\text { tility } & \ldots\end{array}$ & $99 \cdot 2$ & $99 \cdot 9$ & $100 \cdot 0$ & $98 \cdot 6$ & $98 \cdot 5$ & $98 \cdot 7$ \\
\hline
\end{tabular}

(b) Net Increase in Weight of the Linseed Oil.

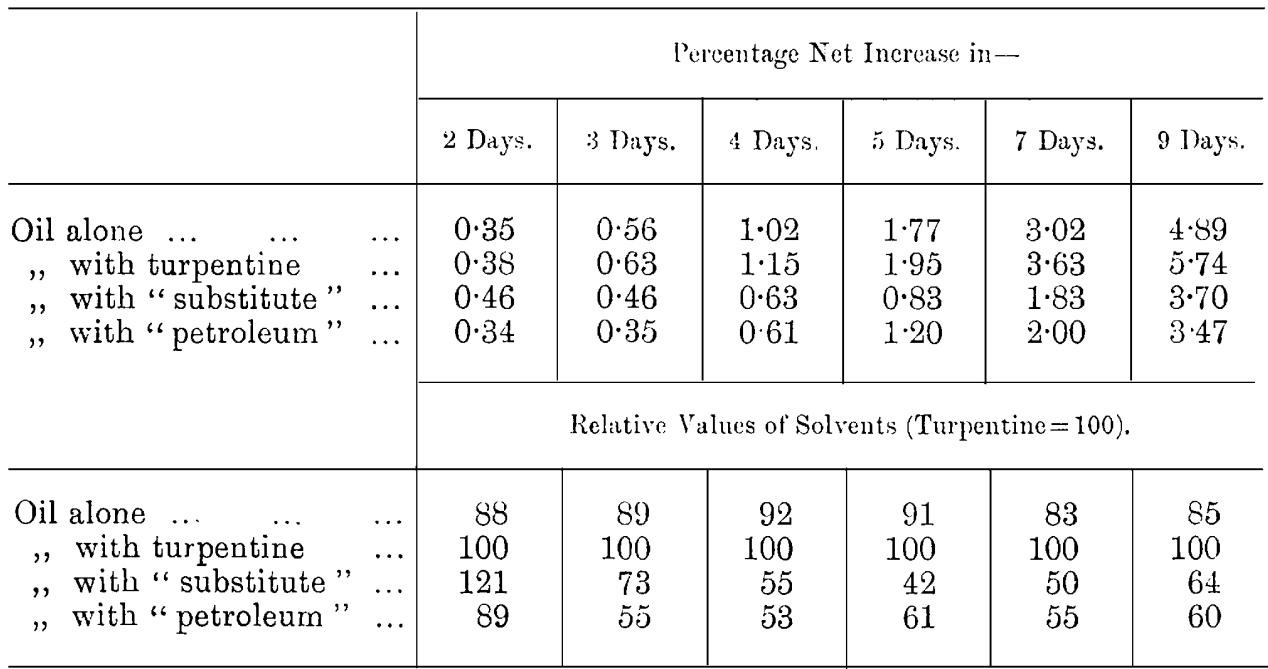

III. Boiled OIL.

(a) Volatility of Solvents.

(Percentage by weight.)

\begin{tabular}{|c|c|c|c|c|c|c|}
\hline \multirow{2}{*}{ Time. } & \multicolumn{3}{|c|}{ Alone. } & \multicolumn{3}{|c|}{ With Non-drying Oil. } \\
\hline & Tumentine. & Substitute. & P'ctroleum. & 'Turpentine & Substitute. & P'stroleum. \\
\hline 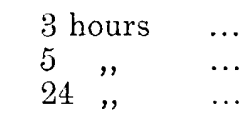 & $\begin{array}{l}78 \cdot 4 \\
98 \cdot 7 \\
99 \cdot 3\end{array}$ & $\begin{array}{l}85 \cdot 0 \\
99 \cdot 5 \\
99 \cdot 9\end{array}$ & $\begin{array}{l}85 \cdot 8 \\
99 \cdot 0 \\
99 \cdot 9\end{array}$ & $\begin{array}{l}71 \cdot 7 \\
93 \cdot 6 \\
98 \cdot 2\end{array}$ & $\begin{array}{l}77 \cdot 5 \\
91 \cdot 6 \\
97 \cdot 5\end{array}$ & $\begin{array}{l}74 \cdot 8 \\
89 \cdot 4 \\
97 \cdot 0\end{array}$ \\
\hline $\begin{array}{cc}\text { Maximum vola- } \\
\text { tility }\end{array}$ & $99 \cdot 3$ & $99 \cdot 9$ & $99 \cdot 9$ & $98 \cdot 6$ & $99 \cdot 1$ & $99 \cdot 0$ \\
\hline
\end{tabular}


(b) Net Increase in Weight of the Linsecd Oil.

\begin{tabular}{|c|c|c|c|c|c|c|c|c|}
\hline & \multicolumn{4}{|c|}{ Percentage Net Increase in- } & \multicolumn{4}{|c|}{$\begin{array}{l}\text { Relative Values of Solvents } \\
\quad \text { (Turpentine }=100)\end{array}$} \\
\hline & 1 Day. & 2 Dilys. & 3 Days. & ¿ Dilys. & 1 Day. & 2 Days. & $\because$ Days. & 5 Days. \\
\hline Oil alone $\quad \ldots \quad \ldots$ & $2 \cdot 73$ & $5 \cdot 40$ & $6 \cdot 60$ & $7 \cdot 59$ & 103 & 96 & 91 & 88 \\
\hline , with turpentine ... & $2 \cdot 65$ & $5 \cdot 61$ & $7 \cdot 27$ & $8 \cdot 63$ & 100 & 100 & 100 & 100 \\
\hline " with " substitute" & $2 \cdot 83$ & $5 \cdot 87$ & $7 \cdot 39$ & $8 \cdot 56$ & 107 & 105 & 102 & 99 \\
\hline " with "petroleum, & $1 \cdot 88$ & $5 \cdot 30$ & $6 \cdot 87$ & $8 \cdot 12$ & 71 & 94 & 94 & 94 \\
\hline
\end{tabular}

IV. BoILED OII.

(a) Volatility of Solvents.

(Percentage by weight.)

\begin{tabular}{|c|c|c|c|c|c|c|}
\hline \multirow{2}{*}{ Time. } & \multicolumn{3}{|c|}{ Alone. } & \multicolumn{3}{|c|}{ With Non-drying Oil. } \\
\hline & Turpentinc. & Substitute. & Petroleum. & Tupentine. & Substitute. & Petroleum. \\
\hline $\begin{array}{ll}3 \text { hours } & \ldots \\
5 & \ldots \\
24, & \ldots\end{array}$ & $\begin{array}{l}98 \cdot 3 \\
99 \cdot 3 \\
99 \cdot 3\end{array}$ & $\begin{array}{r}99 \cdot 7 \\
100 \cdot 0 \\
100 \cdot 0\end{array}$ & $\begin{array}{l}100 \cdot 0 \\
100 \cdot 0 \\
100 \cdot 0\end{array}$ & $\begin{array}{l}95 \cdot 6 \\
97 \cdot 1 \\
98 \cdot 0\end{array}$ & $\begin{array}{l}93 \cdot 5 \\
96 \cdot 1 \\
98 \cdot 2\end{array}$ & $\begin{array}{l}92 \cdot 1 \\
95 \cdot 2 \\
98 \cdot 0\end{array}$ \\
\hline $\begin{array}{c}\text { Maximum vola- } \\
\text { tility }\end{array}$ & $99 \cdot 3$ & $100 \cdot 0$ & $100 \cdot 0$ & $9 S \cdot 3$ & $99 \cdot 0$ & $99 \cdot 0$ \\
\hline
\end{tabular}

(b) Net Increase in Weight of the Linseed Oil.

\begin{tabular}{|c|c|c|c|c|c|c|c|c|}
\hline & \multicolumn{4}{|c|}{ Percentage Net Increase in- } & \multicolumn{4}{|c|}{$\begin{array}{l}\text { Relative Values of Solvents } \\
\text { (Turpentine }=100)\end{array}$} \\
\hline & I Diay. & 2 Days. & 3 I)ays. & 5 Days. & 1 Day. & 2 Iilys. & 3 Days. & 5 Days. \\
\hline Oil alone $\quad \ldots \quad \ldots$ & 3.57 & $6 \cdot 13$ & $7 \cdot 01$ & $7 \cdot 62$ & 94 & 94 & 90 & 86 \\
\hline ", with turpentine ... & $3 \cdot 78$ & 6.51 & $7 \cdot 81$ & $8 \cdot 86$ & 100 & 100 & 100 & 100 \\
\hline " with "substitute" & $3 \cdot 90$ & $6 \cdot 71$ & $7 \cdot 89$ & 8.59 & 103 & 103 & 101 & 97 \\
\hline " with "petroleum" & $2 \cdot 60$ & $\tilde{5} \cdot 41$ & $6 \cdot 80$ & $7 \cdot 67$ & 69 & 83 & 87 & 87 \\
\hline
\end{tabular}

From the above results it is evident that-with a possible exception in the case of raw oil-neither solvent accelerates the drying of linseed oil to any marked extent; but, since the use of a solvent is necessary, if only for thinning, turpentine is, on the whole, the most suitable for the purpose.

The results also indicate, however, that suitable turpentine substitutes (such as the wixture of turpentine and petroleum hydrocarbons used in the experiments) 
may possess such relatively high efficiency as to warrant their employment for many purposes without serious detriment to the work involved and with considerable economy in the cost of solvent.

Chemical Depalimext,

LoNinox Countr Corscit.

\section{Discussion.}

Mr. RAYMOND Ross asked what exactly was meant by "petroleum oil" in this case. The properties of the many different kinds of petroleum oil were by no means the same, there being variable quantities of paraffins, olefines, and naphthenes present, the naphthenes themselves rarying according to the degree of hydrogenation.

Mr. L. Myddelton NAsh said he had taken three different colours, ground in raw oil and thinned with boiled oil, each batch being divided into three portions, which were thinned respectively with (a) American turpentine (unfractionated), as received and used in a colour works; (b) petroleum spirit, as received and as usednot treated by the polymerisation process-having a sp. gr. of 0.800 and the same close flash-point as American turpentine; $(c)$ a mixture of the two in the same proportions. These were painted on primed wood in the ordinary way, and there seemed nothing to choose between them from the point of view of speed of drying. He had made a number of determinations of the amount of residue in American turpentine over several years, and had found the percentage to vary between 0.54 and 1.85, the average being 1.2 . The turpentine was fractionated in the ordinary way to determine the range of boiling-point, and the residue was evaporated on the waterbath to constant weight. That it did not consist of entrained rosin he had proved in two ways-viz., it did not give the Libermann-Storch reaction, and, moreover, contained only 6 to 14 per cent. of acid bodies, whereas rosin contained about 90 per cent. Possibly it was an oxidation product, or polymerised terpenes.

Mr. J. H. Cos'te said that he had made painting experiments with turpentine and with several of the turpentine substitutes referred to in his paper before the Society in 1908, using white lead, ultramarine, burnt siena, and ivory black-i.e., a pigment which had drying properties of its own, and others which had not. His conclusion from these experiments was that, as far as drying was concerned, there was very little to choose between these different solvents. Practical painters, however, held generally the opinion that turpentine was much the best, and it was difficult to persuade them to use anything else. Complaints were sometimes made that paint in which these substitutes were used had an unpleasant smell, but this seemed to be because people were more accustomed to the smell of turpentine than to that of these various hydrocarbons.

The residue from turpentine was certainly not of the nature of ordinary colophony. There was a supposition that this small residue gave turpentine some special advantage, though it was difficult to see what it could be. He thought that the petroleum solvent used by Mr. Powney was probably derived from Borneo petroleum, as some of it which he had examined was a mixture of aliphatic and aromatic hydrocarbons in proportions which, in the light of the work of Jones and 
Wootton (J. Chem. Soc., 1907, 92, 1143), seemed to indicate that it was similar to Borneo oil.

Mr. W. E. Powney said that the sp. gr. of the petroleum spirit was 0.805 to 0.806 , the refractive index 1.4519 at $20^{\circ} \mathrm{C}$., and the flash-point (Abel close test) $79^{\circ} \mathrm{F}$. The material yielded about 3 per cent. boiling up to $140^{\circ} \mathrm{C}$., and 92 per cent. between $140^{\circ}$ and $180^{\circ} \mathrm{C}$.

$$
+\div+\div
$$

